\title{
Impact of removal and restriction of me- too medicines in a hospital drug formulary on in- and outpatient drug prescriptions: interrupted time series design with comparison group
}

\author{
Raquel Vázquez-Mourelle ${ }^{1^{*}}$ (D) Eduardo Carracedo-Martínez ${ }^{2}$ and Adolfo Figueiras ${ }^{3}$
}

\begin{abstract}
Background: The study covered in- and out-of-hospital care in a region in north-western Spain. The intervention evaluated took the form of a change in the hospital drugs formulary. Before the intervention, the formulary contained four of the five low molecular weight heparins (LMWHs) marketed in Spain. The intervention consisted of withdrawing two LMWHs (bemiparin and dalteparin) from the formulary and restricting the use of another (tinzaparin), leaving only enoxaparin as an unrestricted prescription LMWH.

Accordingly, the aim of this study was to evaluate the effect on in- and outpatient drug prescriptions of removing and restricting the use of several LMWHs in a hospital drugs formulary.

Methods: We used a natural, before-after, quasi-experimental design with a control group and monthly data from January 2011 to December 2016. Based on data drawn from official Public Health Service sources, the following dependent variables were extracted: defined daily doses (DDD) per 1000 inhabitants per day (DDD/TID), DDD per 100 stays per day, and expenditure per DDD.

Results: The two compounds that were removed from the formulary registered an immediate decrease at both an intra- and out-of-hospital level $(66.6 \%$ and $55.6 \%$ for bemiparin and $73.0 \%$ and $92.2 \%$ for dalteparin, respectively); similarly, the compound that was restricted also registered an immediate decrease (36.1\% and 9.0\% at the in- and outpatient levels, respectively); in contrast, the remaining LMWH (enoxaparin) registered an immediate, significant increase at both levels (44.9\% and 32.6\%, respectively). The intervention led to an immediate reduction of $6.8 \%$ and a change in trend in out-of-hospital cost/DDD; it also avoided an expenditure of $€ 477,317.1$ in the 21 months following the intervention.
\end{abstract}

Conclusions: The results indicate that changes made in a hospital drugs formulary towards more efficient medications may lead to better use of pharmacotherapeutic resources in its health catchment area.

Keywords: Hospital formulary, Low molecular weight heparin, LMWH, Programme efficiency, Pharmacy and therapeutics committee, Prescription drugs, Cardiovascular drugs

\footnotetext{
* Correspondence: raquel.vazquez.mourelle@sergas.es

${ }^{1}$ Sub-Directorate-General, Galician Health Service (Servicio Gallego de Salud -

SERGAS), Galicia Regional Authority, Santiago de Compostela, Galicia, Spain

Full list of author information is available at the end of the article
}

(c) The Author(s). 2019 Open Access This article is distributed under the terms of the Creative Commons Attribution 4.0 International License (http://creativecommons.org/licenses/by/4.0/), which permits unrestricted use, distribution, and reproduction in any medium, provided you give appropriate credit to the original author(s) and the source, provide a link to the Creative Commons license, and indicate if changes were made. The Creative Commons Public Domain Dedication waiver (http://creativecommons.org/publicdomain/zero/1.0/) applies to the data made available in this article, unless otherwise stated. 


\section{Introduction}

The viability of public health services and their financing is one of the major global health policy debates [1-3], due to the constant increase in costs [4]. Pharmaceutical provision accounts for $25-30 \%$ of the public budgeting of healthcare expenditure [5] and is considered to be the main cause of inefficiency in public health services [1].

The main factors involved in high pharmacy costs are the appearance of new drugs, the intensification of treatments, polytherapy, or their prices [6], the promotion of pharmaceutical companies [7, 8], and the induced prescriptions of hospital doctors to primary care doctors [9-11].

Hospital drugs formularies are lists of drugs drawn up to optimise inpatient care and ensure clinically appropriate, safe and cost-effective access [12, 13], and are a common tool for rational drug use in developed countries [14-16]. The growing supply of available drugs, many of which are so-called "me-too drugs" or drugs from the same family, and intense promotion by the pharmaceutical industry has made it necessary to limit these lists [7]. Although drugs formularies are not strictly mandatory, adherence to them by hospital prescribers tends to be very high [15-18], ranging at maximum from $85 \%$ to $90 \%$ [16].

To our knowledge, there is little research [19-21] evaluating the impact of a change in hospital formularies on outpatient prescription. Hence, the aim of this study was to evaluate the impact of withdrawing two low molecular weight heparins (LMWHs) from a hospital formulary (and restricting a third to the case where the only unrestricted prescription LMWH is contraindicated) on in- and outpatient LMWH prescribing.

\section{Material and methods}

\section{Scope}

The study was carried out in Galicia, a region in northwestern Spain which had 2,718,525 inhabitants in 2016. Ninety-nine percent of the population is covered by the Spanish National Health Service (SNHS) with a public health insurance system; a quarter of the population is over 65 years of age. The range of services offered to citizens includes preventive, diagnostic, therapeutic, rehabilitative, and health promotion and maintenance activities.

Visits to the doctor are free of charge; out-of-hospital pharmaceutical service is subject to a financial contribution (co-payment), whereas in-hospital service is free of charge.

In Spain, the official prices of state-funded medicines dispensed in community pharmacies are set by the State. In the study period, the price of LMWHs did not change. In the hospital setting, each hospital can individually negotiate with the pharmaceutical industry the price to be paid for a drug and each hospital freely defines its own hospital drugs formulary for inpatient use.

By virtue of the regulations in force during the study period, at an out-of-hospital level in Spain, regional governments are not empowered to decide which medicines are subject to prior authorisation: this can only be done by the central government.

Spain currently has $\sim 11,800$ state-funded drugs dispensable under official medical prescription at community pharmacy outlets. Both the funding (degree of reimbursement) and price are set by the central government. There is no published set of rules and regulations governing the criteria applied. Once a medication has been placed on the market, its price tends to remain unchanged until its period of exclusivity expires: it is only then that the price tends to drop due to competition from generic drugs. Spain has a reference price system that categorises drugs according to their active ingredients [22]. There are no formularies in primary care.

Unlike the situation in retail pharmacy outlets, the number of medications included in the hospital drug formulary of these regions' health service does not usually exceed 1000. These drugs are selected by the Pharmacy and Therapeutics Committee and then directly negotiated between the laboratory and hospital pharmacy department concerned.

In Galicia, around 30\% of the health budget for 2017 was allocated to pharmaceuticals as follows: $20 \%$ to drugs dispensed at community pharmacies and about $10 \%$ to hospital pharmacies.

On the basis of the body of available scientific evidence, the different LMWHs cannot be said to display different degrees of efficacy/effectiveness for their indications, with these drugs being regarded as equivalent treatments [23, 24]. Nevertheless, their out-of-hospital costs per defined daily dose (DDD) are very different. The cost/DDD of each LMWH used to calculate the trend in expenditure per DDD of the set of LMWHs at an ambulatory level was bemiparin, €3.90; tinzaparin, $€ 2.85$; enoxaparin, $€ 2.32$; nadroparin, $€ 2.24$; and dalteparin, €2.12.

\section{Design}

We used a natural, before-after, quasi-experimental design with a control group and monthly data from January 2011 to December 2016. This design not only allows for causal effects to be estimated by controlling for baseline level and trend [25], but it also makes full use of the longitudinal nature of the data, a feature that lends the design its special robustness [26, 27].

The use of a control group in interrupted time series studies (ITS) is not compulsory, since pre- and postintervention trends within the study population are compared. Even so, a control group can help to reduce 
confounding caused by external co-interventions. To act as our control group, we therefore selected a health area which had similar characteristics to those of the intervention group and that belonged to the same public health service. This enabled us to control for the possible influence of external factors that affect prescribing, such as the publication of guidelines or articles, alerts pertaining to the medications studied, or pharmaceutical company promotions.

\section{Intervention group}

The Galician Health Service has 7 health areas, one of which is the Santiago de Compostela health area, with a catchment population of 447,699 inhabitants in 2016, a third-level referral hospital with 1043 beds [28], and 74 health centres. Its hospital drugs formulary contained $\sim 700$ drugs. In the intervention group, a change was made to the LMWHs listed in the hospital drugs formulary in February 2015.

\section{Control group}

The Lugo health area had a catchment population of 308,533 inhabitants in 2016, a third-level referral hospital with 879 beds, and 71 health centres. Its hospital drugs formulary contained $\sim 1000$ drugs. It was selected as a control group by virtue of having a similar population and healthcare resources [29]. Furthermore, the intervention and control groups belonged to the same public health service.

In the control group, no changes were made during the study period to the LMWHs in the hospital drugs formulary.

\section{Intervention}

The intervention took the form of a change in the hospital drugs formulary. Before the change, the formulary contained 4 of the 5 LMWHs marketed in Spain. The change consisted of removing bemiparin and dalteparin from the drugs formulary of the Clinical University Teaching Hospital in the Santiago de Compostela health area, as well as restricting tinzaparin (i.e., subject to prior authorisation) to very specific cases (creatinine clearance $<30 \mathrm{ml} / \mathrm{min}$ ). This change took place in February 2015. The only LMWH that remained in the hospital drugs formulary as an unrestricted medication was enoxaparin.

This measure is the consequence of the context described under the head "Scope" regarding out-of-hospital prescription of LMWHs (the cost/DDD of enoxaparin is one of the lowest at retail pharmacy outlets, and its price is non-negotiable in this setting) and the fact that at intra-hospital level, an advantageous reduction was achieved in the unit price of enoxaparin. To our knowledge, there was no other additional intervention implemented by the health authorities in this period.

It should be noted that tinzaparin remained on the formulary because at the time of the change, here in Spain, enoxaparin was contraindicated in patients with severe renal failure. This was not the case with tinzaparin. However, in March 2017, Spain was brought into line with other European countries, with this contraindication being removed from the Spanish summary of enoxaparin product characteristics. Future modifications of the hospital drugs formulary could include the withdrawal of tinzaparin.

\section{Data sources}

The data were drawn from official Public Health Service sources. These sources are of an administrative nature, which implies that the recording of data is populationbased (there is no sampling) and exhaustive (there is practically no risk of under-reporting), with the data being linked to accounting and economic aspects of community and hospital pharmacies.

The Official Hospital Pharmacy Information System (known by its Spanish acronym "SINFHOS") was used for in-hospital data: it shows the purchases made by SNHS hospital pharmacy services for inpatient use.

Data on out-of-hospital prescriptions were obtained from the Official Pharmacy Information System for Complex Pharmacy Service Analyses (known by its Spanish acronym "SIAC_PF"): which shows all drugs dispensed under official medical prescription by community pharmacies in the health area and charged to the SNHS.

\section{Patient and public involvement}

No patients were involved.

\section{Definition of variables}

The number of DDD [30] per month was calculated for each of the five LMWHs marketed in Spain, i.e., bemiparin, dalteparin, enoxaparin, nadroparin, and tinzaparin [31]. A DDD is the assumed average maintenance dose per day for a drug used for its main indication in adults [32].

Accordingly, we calculated the number of DDD per 1000 inhabitants per day (DDD/TID) and the number of DDD per 100 stays per day [33]. These two internationally used basic units of consumption make it possible to examine drug use at both an ambulatory and hospital level in time sequences, without this being affected by changes in such drug's commercial presentation [33].

For the purpose of calculating DDD/TID, the mean population of the study areas was taken into account, and for the purpose of calculating DDD per 100 stays per day, the mean hospital stays were taken into 
account. For both DDD/TID and DDD per 100 stays per day, values were calculated for each month over the study period. Expenditure per DDD was calculated by dividing the entire monthly cost by the number of DDD prescribed that month.

\section{Statistical analysis}

For statistical analysis purposes, we used an interrupted time series (ITS) [27, 34] analysis and constructed a segmented linear regression model for each independent variable analysed.

Adjusting for the values of the control area will show the effects of the intervention, by eliminating the possible influence of external co-interventions. To this end, we used the following equation:

$$
\begin{aligned}
Y_{t}=\beta_{0} & +\beta_{1} T_{t}+\beta_{2} X_{t}+\beta_{3} \mathrm{X}_{\mathrm{t}} \mathrm{T}_{t}+\beta_{4} Z+\beta_{5} \mathrm{ZT}_{t} \\
& +\beta_{6} \mathrm{ZX}_{t}+\beta_{7} \mathrm{ZX}_{t} \mathrm{~T}_{t}+e
\end{aligned}
$$

where

- $Y_{t}$ is the dependent variable with monthly values (DDD/TID, DDD per 100 stays per day, and expenditure per DDD);

- $\beta_{0}$ represents the initial level of the dependent variable;

- $\beta_{1}$ is the slope of the dependent variable until the implementation of the intervention;

- $T_{t}$ is the number of months since the start of the study;

- $\beta_{2}$ represents the change in the level of the dependent variable, which occurs in the period immediately following as compared to the period immediately preceding the implementation of the intervention;

- $X_{t}$ is a dummy variable representing the intervention (pre-intervention period, 1; post-intervention period, $0)$;

- $\beta_{3}$ represents the difference between the pre- and post-intervention periods in the slope of the dependent variable;

- $\mathrm{X}_{\mathrm{t}} \mathrm{T}_{\mathrm{t}}$ is an interaction term;

- $\beta_{4}$ represents the difference in the level of the dependent variable between the intervention area and the control area in the pre-intervention period;

- $Z$ is a dummy variable that denotes cohort assignment (intervention $=0$, control $=1$ );

- $\beta_{5}$ represents the difference in slope of the dependent variable between the intervention area and the control area in the pre-intervention period;

- $\mathrm{ZT}_{t}$ is an interaction term;

- $\beta_{6}$ indicates the difference between the control group and the intervention group in terms of the level of the dependent variable immediately after the intervention;

- $\mathrm{ZX}_{t}$ is an interaction term;

- $\beta_{7}$ represents the difference between the control group and the intervention group in terms of the difference between the slope of the dependent variable after and before the intervention;

- $\mathrm{ZX}_{t} \mathrm{~T}_{t}$ is an interaction term; and,

- $e_{t}$ is the random error term.

As a measure of adjustment of the statistical model, we used the value of $\mathrm{R}_{2}$; to control for possible autocorrelation, auto-regressive terms were introduced into the model.

Based on the regression coefficient $\beta_{6}$, we calculated the percentage reduction in the use of LMWHs with respect to the situation immediately preceding the change in the hospital drugs formulary.

To assess the influence of the control group on the results, we performed a sensitivity analysis, by applying a classical ITS model (without a control group).

\section{Results}

Table 1 shows the population distribution of the intervention and control groups.

\section{In-hospital use}

Table 2 shows the results of the segmented regression. The monthly trend in DDD/100 stays-day for LMWHs at the hospital where the hospital drugs formulary intervention took place showed that

(1) the compounds removed from the formulary [bemiparin and dalteparin] registered an immediate significant decrease: $66.6 \%$ for bemiparin $(p<0.05)$ and $73.0 \%$ for dalteparin $(p<0.01)$;

(2) the compound that was restricted [tinzaparin] also experienced an immediate significant decrease of $36.1 \%(p<0.01)$ and a shift from an upward trend

Table 1 Intervention and control group: demographic data

\begin{tabular}{clc}
\hline Characteristics & $\begin{array}{l}\text { Intervention group } \\
N=445,474\end{array}$ & $\begin{array}{l}\text { Control group } \\
N=317,527\end{array}$ \\
\hline Age-n (\%) & & \\
$0-18$ & $67,347(15.1)$ & $40,825(12.9)$ \\
$19-30$ & $47,669(10.7)$ & $31,163(9.8)$ \\
$31-50$ & $134,660(30.3)$ & $88,068(27.7)$ \\
$51-70$ & $119,066(26.7)$ & $88,665(27.9)$ \\
$>70$ & $76,732(17.2)$ & $68,806(21.7)$ \\
Sex-n (\%) & & \\
Male & $215,653(48.4)$ & $154,065(48.5)$ \\
Female & $229,821(51.5)$ & $163,462(51.4)$ \\
\hline
\end{tabular}


Table 2 Results of controlled interrupted segmented regression of time series

\begin{tabular}{|c|c|c|c|c|c|c|}
\hline & \multirow{2}{*}{\multicolumn{2}{|c|}{ Pre-intervention trend }} & \multicolumn{4}{|c|}{ Post-intervention } \\
\hline & & & \multicolumn{2}{|c|}{$\begin{array}{l}\text { Immediate impact of the formulary } \\
\text { change }\end{array}$} & \multicolumn{2}{|c|}{$\begin{array}{l}\text { Change in trend after the } \\
\text { formulary change }\end{array}$} \\
\hline & Coefficient & $\begin{array}{l}95 \% \text { confidence } \\
\text { interval }\end{array}$ & Coefficient & $\begin{array}{l}95 \% \text { confidence } \\
\text { interval }\end{array}$ & Coefficient & $\begin{array}{l}95 \% \text { confidence } \\
\text { interval }\end{array}$ \\
\hline \multicolumn{7}{|l|}{$\mathrm{DDD} / \mathrm{TID}$} \\
\hline $\begin{array}{l}\text { Total low molecular weight } \\
\text { heparins }\end{array}$ & -0.00368 & -0.01652 to 0.00916 & -0.22475 & -0.84762 to 0.39812 & 0.03792 & -0.00526 to 0.08110 \\
\hline Enoxaparin $^{a}$ & $-0.02868^{*}$ & -0.03783 to -0.01953 & $0.83432^{*}$ & 0.40110 to 1.26754 & $0.06759^{*}$ & 0.03701 to 0.09817 \\
\hline Bemiparin $^{\text {b }}$ & $0.00739^{*}$ & 0.00165 to 0.01313 & $-0.44664^{*}$ & -0.70761 to -0.18567 & $-0.02817^{*}$ & -0.04681 to -0.00953 \\
\hline Tinzaparin $^{c}$ & $0.013880^{*}$ & 0.00651 to 0.02125 & $-0.26654^{*}$ & -0.45942 to -0.07366 & -0.00187 & -0.01381 to 0.01007 \\
\hline Dalteparin ${ }^{b}$ & $-0.00071^{*}$ & -0.00136 to -0.00006 & $-0.02773^{*}$ & -0.05092 to -0.00454 & 0.00141 & -0.00012 to 0.00294 \\
\hline Nadroparin $^{d}$ & $0.00062^{*}$ & 0.00005 to 0.00119 & 0.00459 & -0.01871 to 0.02789 & -0.00043 & -0.00200 to 0.00114 \\
\hline \multicolumn{7}{|l|}{ DDD/100 stays and day } \\
\hline $\begin{array}{l}\text { Total low molecular weight } \\
\text { heparins }\end{array}$ & -0.27284 & -0.91964 to 0.37396 & 14.51816 & $\begin{array}{l}-13.64694 \text { to } \\
42.68326\end{array}$ & -1.80935 & -3.80400 to 0.18530 \\
\hline Enoxaparin $^{a}$ & -0.40854 & -1.01540 to 0.19832 & $41.83919^{*}$ & 15.89330 to 67.78508 & -0.20613 & -2.10147 to 1.68921 \\
\hline Bemiparin $^{b}$ & $-0.24035^{*}$ & -0.42506 to -0.05564 & $-8.06595^{*}$ & $\begin{array}{l}-15.39245 \text { to }- \\
0.73945\end{array}$ & $-0.88081^{*}$ & -1.42010 to -0.34152 \\
\hline Tinzaparin $^{c}$ & $0.51274^{*}$ & 0.33291 to 0.69257 & $-\overline{12.50797^{*}}$ & $\begin{array}{l}-16.85966 \text { to }- \\
8.15628\end{array}$ & $-0.51714^{*}$ & -0.82116 to -0.21312 \\
\hline Dalteparin ${ }^{\mathrm{b}}$ & $-0.06482^{*}$ & -0.09016 to -0.03948 & $-1.25262^{*}$ & -2.15101 to -0.35423 & 0.04139 & -0.01988 to 0.10266 \\
\hline Nadroparin $^{d}$ & -0.00018 & -0.00098 to 0.00062 & 0.01117 & -0.02974 to 0.05208 & 0.00016 & -0.00268 to 0.00300 \\
\hline \multicolumn{7}{|l|}{ Outpatient expenditure per DDD } \\
\hline $\begin{array}{l}\text { Total low molecular weight } \\
\text { heparins }\end{array}$ & $0.00517^{*}$ & 0.00395 to 0.00639 & $-0.11977^{*}$ & -0.17028 to -0.06926 & $-0.00786^{*}$ & -0.01139 to -0.00433 \\
\hline
\end{tabular}

before the change to a long-term downward trend $(p<0.01)$; and,

(3) the LMWH that remained in the formulary as the first choice [enoxaparin] displayed a sharp change in consumption, going from a previous downward trend to an immediate increase of $44.9 \%(p<0.01)$.

With respect to the sum of antithrombotic drugs other than LMWHs, there were no significant differences $(p>$ 0.05).

\section{Outpatient use}

Figure 1 depicts the monthly trend in out-of-hospital DDD/TIDs for the sum of the five LMWHs and for each individually.

Table 2 shows the results of the segmented regression.

(1) In the case of the LMWHs that were withdrawn from the hospital drugs formulary, the effect of the intervention on bemiparin use was to change its previous upward trend $(p<0.05)$ to an immediate significant reduction of $55.6 \%(p<0.01)$ and a longterm downward trend $(p<0.01)$. Dalteparin, which had shown decreasing use before the change to the hospital drugs formulary $(p<0.05)$, registered an immediate significant reduction of $92.2 \%$ postintervention $(p<0.05)$.

(2) In the case of the LMWH that was restricted (subject to prior authorisation)[tinzaparin], its consumption pattern shifted from a previous upward trend $(p<0.01)$ to an immediate significant reduction of $9.0 \%$ post-intervention $(p<0.01)$.

(3) Use of the only LMWH remaining in the hospital drugs formulary as an unrestricted prescription drug (enoxaparin) changed sharply from a previous long-term downward trend $(p<0.01)$ to an immediate significant increase of $32.6 \%(p<0.01)$ and a long-term upward trend post-intervention $(p<0.01)$.

(4) The only LMWH marketed which was not included in the in-hospital formulary before the change was the one with the lowest out-of-hospital use 

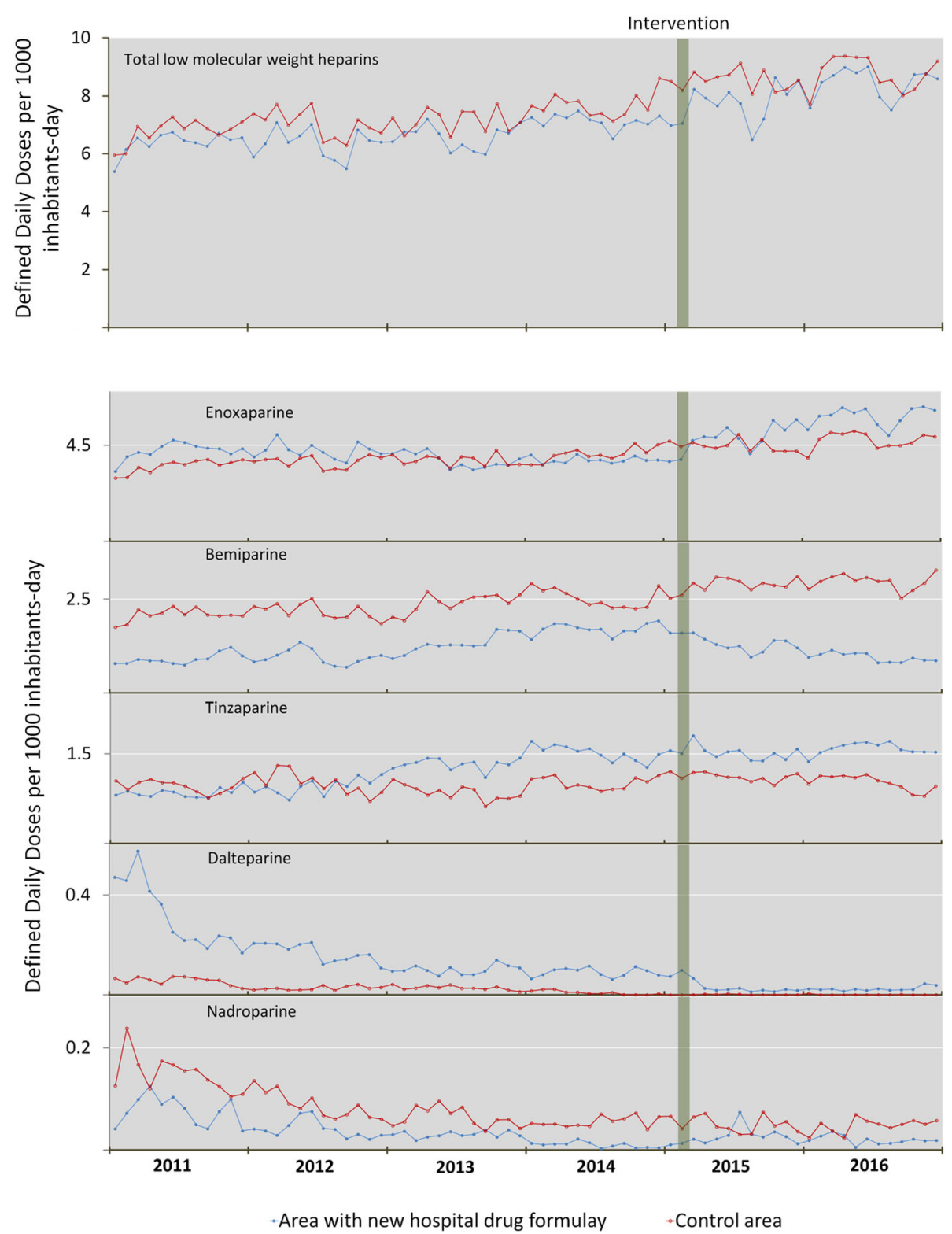

Fig. 1 Trends in out-of-hospital low molecular weight heparin use

(nadroparin). Indeed, it displayed a downward trend. The modification to the hospital drugs formulary resulted in no statistically significant change in this drug's use $(p>0.05)$.

Similarly, the sum of all antithrombotic drugs other than LMWHs showed no significant change after the formulary modifications $(p>0.05)$.

\section{Results in the costs of both scenarios}

Most of the total gross cost of LMWHs during the study period (95\%) was attributable to out-of-hospital use (with average monthly gross expenditure being $€ 13,454$ for in- hospital use versus $€ 256,980$ for out-of-hospital use). In contrast to the in-hospital level, at the out-of-hospital level, costs were correlated with drug use. Figure 2 shows the monthly expenditure per DDD of the sum of LMWHs consumed out-of-hospital in both areas. The upward trend in the intervention area in the period preceding the change $(p<0.01)$ was followed by an immediate significant decrease of $6.8 \%,(p<0.01)$ and a long-term downward trend after the intervention $(p<0.01)$.

Figure 3 illustrates expenditure on DDD in- and outpatient levels in the area of hospital intervention; the cost of DDD was much lower at the in-patient than at the outpatient level and displayed large variations 


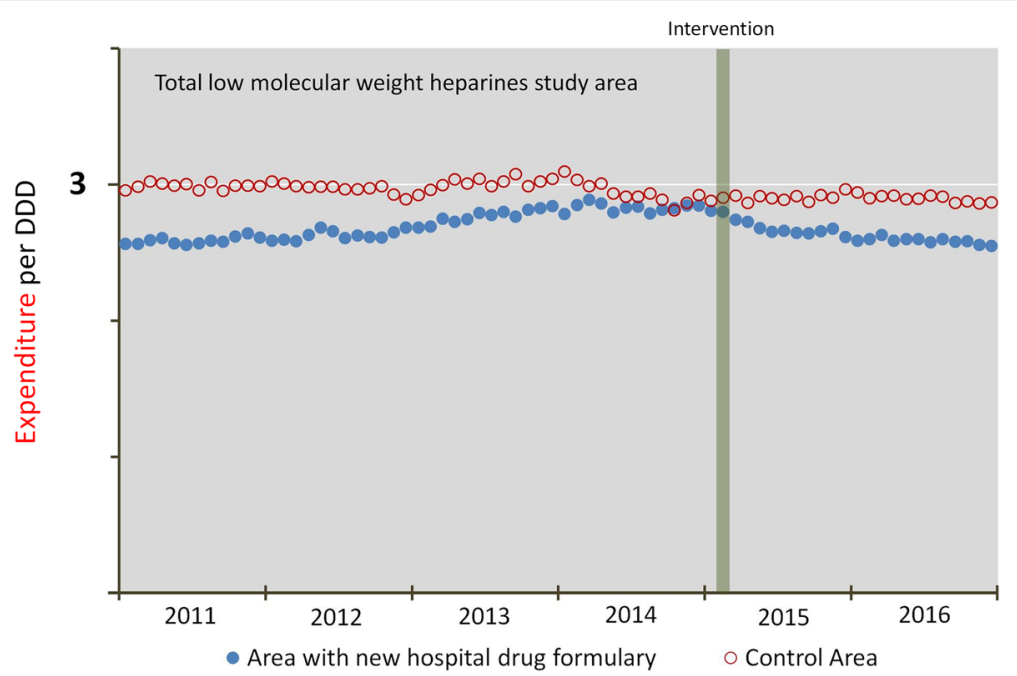

Fig. 2 Out-of-hospital expenditure per defined daily dose (DDD)

throughout the study period, something that did not occur in the outpatient setting. The change in the formulary led to a savings of $€ 477,317.1$ for the SNHS over the 21 months analysed post-intervention. The expenditure avoided in this way corresponded almost entirely to the out-of-hospital setting.

\section{Sensitivity analysis}

Additional file 1: Table S1 lists the results of the segmented regression, which shows the effect of the intervention without the control group [26]. The pattern observed was the same, in terms of both direction and significance, as seen in the analysis with the control group.

\section{Discussion}

This is the first longitudinal controlled study to show that in-hospital LMWH prescribing has a major impact on out-of-hospital prescribing.

Our study intervention (which was in-hospital) led to an immediate decrease of almost $8 \%$ and a shift from upward to downward in the long-term trend of out-ofhospital expenditure per DDD. These results may well be of great interest to policymakers, as they indicate that hospitals are an important inducer of prescribing in primary care and, by extension, that changes in a hospital drugs formulary towards more efficient drugs can help reduce pharmaceutical costs, not only at an in-hospital but also at an out-of-hospital level [9, 10, $11,19,20,35]$.

Our data indicate that the withdrawal of drugs from a hospital drugs formulary has an impact on out-of-hospital prescribing, both in the short and in the long term. An example of this is provided by bemiparin: in addition to registering an immediate reduction in use, it showed a shift in trend, from upwards before its removal from the hospital formulary to downwards thereafter. Similarly, the use of dalteparin, which showed a previous downward trend, registered an immediate significant reduction after the drug's withdrawal.

Although there may be some residual use of some withdrawn medications, this is in line with other studies which indicate that adherence to drugs formularies by hospital health professionals, albeit very high (80-95\%) [15-17], is not $100 \%$.

Our data indicate that the introduction of drug-use restrictions in a hospital formulary is associated with a reduction in that drug's use at both an in- and out-ofhospital level. This is the case of tinzaparin, which, after being made subject to prior authorisation, immediately registered a $45.5 \%$ reduction in consumption in the hospital environment. These results are in line with studies that report a sharp decrease in the use of drugs rendered subject to prior authorisation [36-41].

However, in addition to the restriction's impact on inhospital prescriptions, there was also an impact outside the hospital, with an immediate $9 \%$ reduction in tinzaparin use, despite the fact that the need for prior authorisation was not implemented at the outpatient level. Since, we were unable to locate any other study which analysed the impact of making a drug subject to prior authorisation at the in-hospital level on the prescription of that same drug at the out-of-hospital level (when, at the hospital level, such a drug was not subject to prior authorization), this would make our study the first to analyse such an impact.

At the outpatient level, nadroparin (the only LMWH that was not included in the hospital drugs formulary before the change) experienced no significant changes after the intervention. Moreover, nadroparin is the LMWH 

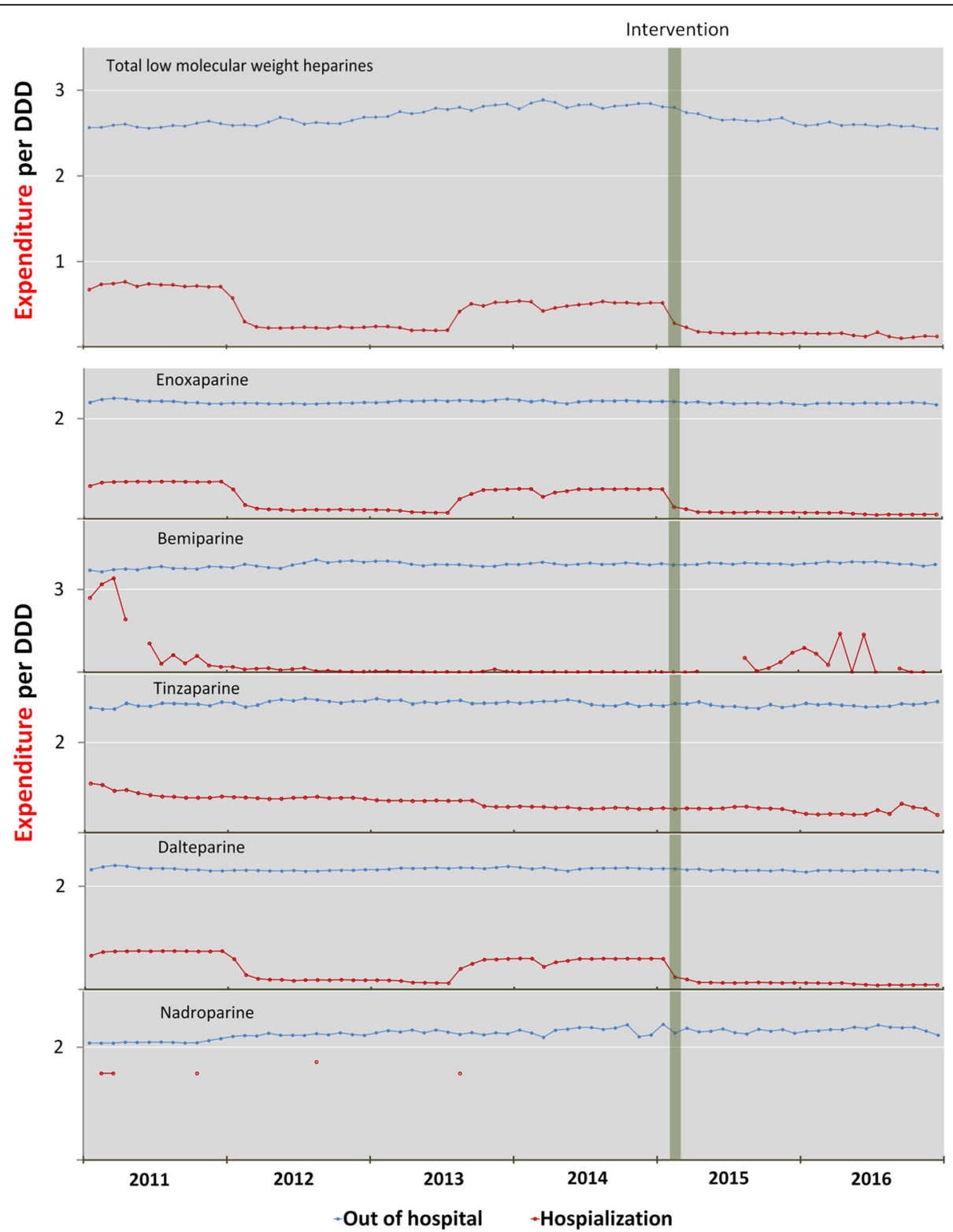

Fig. 3 Out-of-hospital and in-hospital expenditure per defined daily dose (DDD) in the intervention area

with the lowest out-of-hospital use, which further reinforces the theory that in-hospital prescribing has an influence on out-of-hospital prescribing, and is a similar result to that of other cross-sectional studies which report that, when hospitals include a given LMWH in the hospital drugs formulary, there is also greater use of that LMWH at the out-of-hospital level [19].

The finding that $95 \%$ of total SNHS expenditure on LMWHs corresponds to out-of-hospital use may be due to the fact that the number of ambulatory patients in the health area is much higher than the number of patients who are hospitalised at any given time and that out-ofhospital use is usually chronic, while in-hospital use tends to be acute. Furthermore, expenditure per DDD at the in- hospital level is lower than at the out-of-hospital level, as it can be subject to discounts. This would explain why the savings yielded by the change to the hospital drugs formulary during the study period correspond almost entirely to the out-of-hospital setting. Biosimilar enoxaparin was not yet being marketed in Spain by the time our study ended; however, once biosimilar enoxaparin [42-44] is marketed in Spain, the savings could be even greater. The fact that costs correlate with consumption at an out-of-hospital but not at an in-hospital level and the large variations in expenditure per DDD in the in-hospital setting (see Fig. 3) may both be related to the discounts offered by pharmaceutical companies to hospitals, as described in other studies [11, 14]. 
The results of our study indicate that the withdrawal of inefficient drugs from a hospital drugs formulary at an out-of-hospital level and the application of out-ofhospital costs when deciding on the inclusion of a drug in the hospital drugs formulary are aspects that should be taken into account by the committees that decide on the composition of such formularies. Although gross inhospital spending on a group of drugs may be very small compared to what is spent on an out-of-hospital basis for the same group (e.g., LMWHs, anti-hypertensives or proton pump inhibitors), in-hospital formulary changes may have a considerable induced impact on outpatient drug spending.

Pharmacy and Therapeutics Committees play a major role in establishing a local, safe, and effective drug policy [45-47], yet we found no studies addressing how and when a drug should be withdrawn from a hospital drugs formulary. Our results suggest incorporating the withdrawal of inefficient drugs as another essential function. In this connection, it should be noted that this function of evaluating the withdrawal of drugs from the hospital drugs formulary comes at practically zero cost to the health organisation.

To our knowledge, this is the only controlled longitudinal study to analyse the effect of removing a compound from a hospital drugs formulary in two care scenarios, i.e., inpatient and outpatient, and shows that the effect of hospital-induced prescribing on the primary care setting can be modified to guide the latter towards a more efficient drug provision.

The fact that this study was controlled had the advantage that, if there had been changes in consumption or external factors (publications of guides, articles, commercial pressure, safety alerts), this would have been similar in both health areas. In addition, ITS analyses have the advantage that confounding is seldom a problem, since population characteristics (structure by age, sex, educational level, and disease prevalence) tend to change gradually over an extended period of time [48, 49].

In some cases, the intervention and control groups are not perfectly parallel in the pre-intervention period. Here, the data of other potential control groups did not serve as a comparator for our study, in that they did not have the drug which was withdrawn and caused the change in the formulary. To assess the influence of the control group on the results, we conducted a sensitivity analysis by applying a classical ITS model (without a control group). The results were found to be very similar, something that goes to reinforce this study's conclusions.

As in any observational study with drugs, the absolute value of the variables DDD per day-stay and cost per DDD is limited by the characteristics of hospitals, in terms of activity and care provision. However, we believe that the effects on the trend over time in their use can be extrapolated.

\section{Conclusion}

Given that the resources of health systems are limited and that pharmaceutical expenditure is a high percentage of their expenditure, hospital drug formularies can be a very useful and effective tool for improving out-of-hospital prescription profiles in an area and can contain the cost increases associated with drug provision. This is especially important when one recalls that the evaluation of a given drug's removal comes at zero cost to the organisation. This measure can be implemented in any setting that has a hospital drugs formulary. The hospital can therefore become a generator of good prescribing practices and induce a more efficient use of pharmaco-therapeutic resources in its health catchment area.

\section{Additional file}

Additional file 1: Table S1. Results of the interrupted segmented regression without a control group (DOC $52 \mathrm{~kb}$ )

\section{Abbreviations}

DDD: Defined daily doses; DDD/100 s-d: Defined daily doses per 100 stays and a day; DDD/TID: Defined daily doses per 1000 inhabitants per day; LMWHs: Low molecular weight heparins; SNHS: Spanish National Health Service

\section{Acknowledgements}

Not applicable

\section{Authors' contributions}

RVM conceived the study and collected, validated, and standardised the data; AFG and ECM developed the methodological design of the study; and all three authors jointly interpreted the data and results. RVM wrote the paper, and ECM and AFG were responsible for the critical review of the different versions, making major contributions. All authors approved the final version of the manuscript.

\section{Funding}

No funding.

Availability of data and materials

The datasets used and/or analysed during the current study are available from the corresponding author on reasonable request.

Ethics approval and consent to participate

Not applicable

Consent for publication

Not applicable

Competing interests

The authors declare that they have no competing interests.

Author details

${ }^{1}$ Sub-Directorate-General, Galician Health Service (Servicio Gallego de Salud SERGAS), Galicia Regional Authority, Santiago de Compostela, Galicia, Spain. ${ }^{2}$ Santiago de Compostela Health Area Authority, Galician Health Service, Santiago de Compostela, Galicia, Spain. ${ }^{3}$ Department of Preventive Medicine and Public Health, Faculty of Medicine, University of Santiago de Compostela and Consortium for Biomedical Research in Epidemiology and Public Health 
(CIBER en Epidemiología y Salud Pública - CIBERESP), Santiago de Compostela, Galicia, Spain.

\section{Received: 28 December 2018 Accepted: 9 July 2019 Published online: 24 July 2019}

\section{References}

1. Health systems financing. The path to universal coverage. Executive summary. The world health report. 2010. http://www.who.int/whr/2010/10_ summary_en.pdf?ua=1. Accessed 15 Jun 2018.

2. The Organization for Economic Co-operation and Development (OECD). Fiscal sustainability of health systems. bridging health and finance perspectives. 2015. https://www.oecd.org/gov/budgeting/Fiscal-Sustainability-of-Health-SystemsPolicy-Brief-ENG.pdf. Accessed 15 Jun 2018.

3. Peiró M. Funding the gap. El futuro del sistema sanitario: ¿será posible financiar el sistema y reducir las desigualdades en salud?. 2017. https:// www.antares-consulting.com/es_ES/main/detallepublicacion/Publicacion/12 7/apartado/H/idUnidad/3. Accessed 15 Jan 2018.

4. Sánchez-Martínez, F.I., Méndez-Martínez, I., Martínez-Pérez, J.E., Abellá Perpiñán, J.M. El sistema sanitario público en España y sus comunidades autónomas. Sostenibilidad y reformas. 2013. https://www.fbbva.es/wpcontent/uploads/2017/05/dat/DE_2013_IVIE_sistema_sanitario.pdf. Accessed 15 Jan 2018

5. Soto-Alvarez J. Evaluación Económica de Medicamentos y Tecnologías Sanitarias: Principios, Métodos y Aplicaciones en Política Sanitaria. Springer SBM Spain; 2012. p. 9-325

6. Mousnad MA, Shafie AA, Ibrahim MI. Systematic review of factors affecting pharmaceutical expenditures. Health Policy. 2014;16:137-46.

7. Pearce MJ, Begg EJ. A review of limited lists and formularies: are they cost-effective? Pharmacoeconomics. 1992;1:191-202.

8. Spurling GK, Mansfield PR, Montogomery BD, Lexchin J, Doust J, Othman N, et al. Information from pharmaceutical companies and the quality, quantity, and cost of physicians' prescribing: a systematic review. PLoS Med. 2010;19:1-22.

9. Robertson J, Fryer JL, O'Connell DL, Sprogis A, Henry DA. The impact of specialists on prescribing by general practitioners. Med J. 2011;175:407-11.

10. Florentinus SR, Heerdink ER, van Dijk L, Griens F, Groenewegen PP, Leufkens HGM. Is new drug prescribing in primary care specialist induced? BMC Health Serv Res. 2009;9:1-6.

11. Grimmsmann T, Schwabe U, Himmel W. The influence of hospitalisation on drug prescription in primary care-a large-scale follow-up study. Eur J Clin Pharmacol. 2007;63:783-90.

12. American Society of Hospital Pharmacy. ASHP guidelines on the pharmacy and therapeutics committee and the formulary system. Am J Health-Syst Pharm. 2008:65:1272-83.

13. World Health Organization. Managing access to medicines and health technologies. Part III: Management support systems. Hospital pharmacy management. 2012. Available from: http://apps.who.int/medicinedocs/ documents/s19622en/s19622en.pdf. Accessed 20 Jun 2018

14. Gallini A, Juillard-Condat B, Saux MC, Taboulet F. Drug selection in French university hospitals: analysis of formularies for nine competitive pharmacological classes. Br J Clin Pharmacol. 2011;72:823-31.

15. Plet HT, Hallas J, Kjeldsen L. Adherence to hospital drug formularies and cost of drugs in hospitals in Denmark. Eur J Clin Pharmacol. 2013:69:1837-43.

16. Plet HT, Kjeldsen LJ, Christensen Rde P, Nielsen GS, Hallas J. Do educational meetings and group detailing change adherence to drug formularies in hospitals? A cluster randomized controlled trial. Eur J Clin Pharmacol. 2014; 70(1):109-16.

17. Fijn R, Lenderik AW, Egberts ACG, Brouwers JRBJ, De Jong-Van DenBerg LTW. Assessment of indicators for hospital drug formulary non adherence. Eur J Clin Pharmacol. 2001;57:677-84.

18. Gustafsson LL, Wettermark B, Godman B, Andersén-Karlsson E, Bergman U, Hasselström J, et al. The 'wise list'- a comprehensive concept to select, communicate and achieve adherence to recommendations of essential drugs in ambulatory care in Stockholm. Basic Clin Pharmacol Toxicol. 2011; 108:224-33.

19. Gallini A, Legal R, Taboulet F. The influence of drug use in university hospitals on the pharmaceutical consumption in their surrounding communities. Br J Clin Pharmacol. 2013;75:1142-8.

20. Larsen MD, Schou M, Kristiansen AS, Hallas J. The influence of hospital drug formulary policies on the prescribing patterns of proton pump inhibitors in primary care. Eur J Clin Pharmacol. 2014;70:859-65.
21. Vázquez-Mourelle R, Carracedo-Martinez E. The influence of changes in hospital drug formulary on the prescription of proton pump inhibitors. Farm Hosp. 2017:41:49-67.

22. Real Decreto $177 / 2014$, de 21 de marzo, por el que se regula el sistema de precios de referencia y de agrupaciones homogéneas en el Sistema Nacional de Salud, y determinados sistemas de información en materia de financiación y precios de los medicamentos y productos sanitarios. 2014. Available from: https:// www.boe.es/buscar/pdf/2014/BOE-A-2014-3189-consolidado.pdf. Accessed 17 May 2019

23. Valentine KA, Hull RD. Therapeutic use of heparin and low molecular weight heparin. Uptodate. 2012. Available from: https://www.uptodate.com/ contents/heparin-and-Imw-heparin-dosing-and-adverse-effects. Accessed 17 May 2019.

24. Osakidetza. Heparinas de bajos peso molecular en atención primaria. Infac. 2012;20(9):53-38 Available at: http://www.euskadi.eus/contenidos/ informacion/cevime_infac_2012/es_def/adjuntos/INFAC_Vol_20_n_9.pdf.

25. Sruamsiri R, Wagner AK, Ross-Degnan D, Lu CY, Dhippayom T, Ngorsuraches $\mathrm{S}$, et al. Expanding access to high-cost medicines through the E2 access program in Thailand: effects on utilisation, health outcomes and cost using an interrupted time-series analysis. BMJ Open. 2016;6(3):e008671.

26. Kontopantelis E, Doran T, Springate DA, Buchan I, Reeves D. Regression based quasi-experimental approach when randomisation is not an option: interrupted time series analysis. BMJ. 2015;350:h2750

27. Wagner AK, Soumerai SB, Zhang F, Ross-Degnan D. Segmented regression analysis of interrupted time series studies in medication use research. J Clin Pharm Ther. 2002;27(4):299-309.

28. Gerencia de Gestión Integrada de Santiago de Compostela. https:// xxisantiago.sergas.es/Paxinas/web.aspx?tipo=paxtab\&idLista=3\&idContido= 183\&migtab=174\%3B183\&idioma=es. Accessed 20 Sept 2018.

29. Hospital universitario Lucus Augusti. 2017. https://xxilugo.sergas.es/Paxinas/ web.aspx?tipo=paxtab\&idLista=3\&idContido=7\&migtab=7\&idioma=es Accessed 20 Sept 2018.

30. World Health Organisation. WHO Collaborating Centre for Drug Statistics Methodology. https://www.whocc.no/. Accessed 20 Sept 2018.

31. Agencia Española de Medicamentos y Productos Sanitarios. Centro de información de medicamentos. Encuentra tu medicamento aquí. https:// www.aemps.gob.es/cima/publico/home.html. Accessed 20 Sept 2017.

32. World Health Organisation. WHO Collaborating Centre for Drug Statistics Methodology. Definition and general considerations. https://www.whocc. no/ddd/definition_and_general_considera/. Accessed 20 Sept 2017.

33. Laporte JR, Tognoni G. Los principios de epidemiología del medicamento. Masson Salvat Medicine; 2007. p. 67-87.

34. Linden A, Arbor A. Conducting interrupted time-series analysis for single and multiple group comparisons. Stata J. 2015;15(2):480-500.

35. Lapointe-Shaw L, Fischer HD, Newman A, Baptiste AJ, Anderson GM, Rochon PA, et al. Potential savings of harmonising hospital and community formularies for chronic disease medications initiated in hospital. PLoS One. 2012;7(6):e39737.

36. Dassner AM, Girotto JE. Evaluation of a second-sign process for antimicrobial prior authorization. J Pediatric Infect Dis Soc. 2018;7(2):113-8. https://doi.org/10.1093/jpids/pix015

37. Carracedo-Martínez E, Pia-Morandeira A, Figueiras A. Impact of a health safety warning and prior authorisation on the use of piroxicam: a time-series study. Pharmacoepidemiol Drug Saf. 2012;21(3):281 4.

38. Chinitz DP, Waitman DA, Kahan E. When gatekeepers meet the sentinel: the impact of a prior authorization requirement for cefuroxime on the prescribing behaviour of community-based physicians. Br J Clin Pharmacol. 2006;61(3):341-4.

39. Godman B, Sakshaug S, Berg C, Wettermark B, et al. Combination of prescribing restrictions and policies to engineer low prices to reduce reimbursement costs. Expert Rev Pharmacoecon Outcomes Res. 2011;11(1):121 9.

40. O'Connor AB, Lang VJ, Quill TE. Eliminating analgesic meperidine use with a supported formulary restriction. Am J Med. 2005;118(8):885 9

41. Benner KW, Durham SH. Meperidine restriction in a pediatric hospital. J Pediatr Pharmacol Ther. 2011;16(3):185-90.

42. Generics ands biosimilars initiative. FDA approves first biosimilar enoxaparin sodium. 2016. http://www.gabionline.net/Biosimilars/General/Biosimilarsapproved-in-Europe. Accessed 20 sept 2017

43. European Medicines Agency (EMA). Meeting highlights from the Committee for Medicinal Products for Human Use (CHMP). 2016. http:// www.ema.europa.eu/ema/index.jsp?curl=pages/news_and_events/news/2 
016/07/news_detail_002571.jsp\&mid=WC0b01ac058004d5c1.Accessed 20 Sept 2017.

44. European Medicines Agency (EMA). Committee for Medicinal Products for Human Use. Inhixa. 2016. http://www.ema.europa.eu/docs/en_GB/ document_library/Summary_of_opinion__Initial_authorisation/human/ 004264/WC500210836.pdf. Accessed 20 Sept 2017.

45. World Health Organisation (WHO). Drug and therapeutics committees - A practical guide. 2003. http://apps.who.int/medicinedocs/pdf/s4882e/s4882e, pdf. Accessed 20 Sept 2017.

46. Duran-Garcia E, Santos-Ramos B, Puigventos-Latorre F, Ortega A. Literature review on the structure and operation of Pharmacy and Therapeutics Committees. Int J Clin Pharm. 2011;33:475-83.

47. Puigventós F, Santos-Ramos B, Ortega A, Durán-García E. Structure and procedures of the pharmacy and therapeutic committees in Spanish hospitals. Pharm World Sci. 2010;32(6):767-75.

48. Lopez Bernal J, Cummins S, Gasparrini A. The use of controls in interrupted time series studies of public health interventions. Int J Epidemiol. 2018;47(6):2082-93.

49. Soumerai SB, Starr D, Majumdar SR. How do you know which health care effectiveness research you can trust? A guide to study design for the perplexed Prev Chronic Dis. 2015;12:E101.

\section{Publisher's Note}

Springer Nature remains neutral with regard to jurisdictional claims in published maps and institutional affiliations.

Ready to submit your research? Choose BMC and benefit from:

- fast, convenient online submission

- thorough peer review by experienced researchers in your field

- rapid publication on acceptance

- support for research data, including large and complex data types

- gold Open Access which fosters wider collaboration and increased citations

- maximum visibility for your research: over $100 \mathrm{M}$ website views per year

At $\mathrm{BMC}$, research is always in progress.

Learn more biomedcentral.com/submissions 